\title{
A Case Study on the Growth Pattern of Indian Free-ranging Dog in Natural Environment
}

Tanima Choudhury

10.18805/ag.D-5252

\begin{abstract}
Background: The Indian kennel club has determined the weight and height characteristics of adult Indian free-ranging dogs but not for the puppies despite the dogs existing in India for centuries. The formation of a growth chart for these dogs may help veterinarians to be better able to determine the age and health status of the rescued puppies.

Methods: In this study, the weekly weight gains and monthly total length increases of a female Indian free-ranging puppy were observed from $5^{\text {th }}-22^{\text {nd }}$ week of the puppy's life in order to form a growth chart. The puppy's life during observation was divided into three phases-pre-weaned, weaned and scavenge by itself. The mother's monthly weight gain was measured.

Result: The puppy showed $0.71 \pm 0.30 \mathrm{~kg}$ in the first, $0.45 \pm 0.48 \mathrm{~kg}$ in the second and $0.38 \pm 0.40 \mathrm{~kg}$ increase in the third phase of the observation period. No significant difference in weight gain was observed in the three phases. The monthly weight gain and length increase were $1.95 \pm 0.587 \mathrm{~kg}$ and $21.25 \pm 19.05 \mathrm{~cm}$ respectively. No correlation was observed between them. No correlation between months after birth and mother's weight gain were observed.
\end{abstract}

Key words: Growth pattern, Indian free-ranging dog, Weaning.

\section{INTRODUCTION}

The process of dog domestication began in the Upper Palaeolithic period (35,000 years before present) (Davis and Valla,1978). The closest living relative of modern domestic canids is the gray wolf (Canis lupus lupus) (Serpell, 1995). During the process of domestication, domestic dogs have undergone both behavioural and physiological changes. The dogs have undergone directional selection in the genes involved in starch digestion. The selection led to a nearly seventeen fold increase in the gene copy number of Amy2B which codes for a pancreatic amylase (Ollivier et al., 2016). The pancreatic amylase helps to break down starch into maltose and maltotriose enabling the dogs to better survive on a starch rich diet than their carnivorous ancestors.

Free-ranging dogs (Canis lupus familiaris) are mainly unowned dogs that are found both in the urban and rural habitats. They are found anywhere near human settlements from metropolitan cities to forested areas (Vanak and Gompper, 2009). These dogs are scavengers living off of garbage produced by the humans. Indian free-ranging dogs live in an environment rich in starch but poor in protein based foods (Bhadra and Bhadra, 2014). Indian free-ranging dogs live either solitarily or in small groups on the streets. They are diestrous (Pal, 2003). Only one litter is produced per year. Weaning usually begins around 5 weeks old and is completed around 11 weeks old (Pal, 2005; Pal, 2008). At the 5 weeks stage of the puppies' lives the mother provides them with regurgitated food along with milk. As the puppies become older the mother shares her scavenged food with the puppies. Soon after completion of weaning the mother begins to compete with the puppies for food (Majumdar et al., 2014). Competition for food is high among free-ranging dogs
West Bengal State University, Barasat, Kolkata-700 126, West Bengal, India.

Corresponding Author: Tanima Choudhury, Animal Behaviour and Natural Product Research Laboratory, Department of Zoology, West Bengal State University, Barasat, Kolkata-700 126, West Bengal, India. Email: tanimachoudhury91@gmail.com

How to cite this article: Choudhury, T. (2021). A Case Study on the Growth Pattern of Indian Free-ranging Dog in Natural Environment. Agricultural Science Digest. 41(3): 511-515. DOI: 10.18805/ag.D-5252. Submitted: $25-08-2020 \quad$ Accepted: $12-12-2020 \quad$ Online: 02-02-2021 and puppies have to compete with other adult dogs including their own mother for food (Pal et al., 1998). The difficulty in obtaining food could cause retarded growth and development of Indian free-ranging puppies compared to pet dogs where the owners provide food.

Unlike pet dogs it is difficult to obtain detailed weight charts regarding the growth pattern of Indian free ranging puppies. The weight characteristics of adult Indian freeranging dogs have been obtained by the Indian kennel club but no such information regarding the puppies is available. This problem could be due to the fact that although the adult dogs are quite friendly towards people, the mother dogs tend to become aggressive towards unknown people who try to approach her puppies. The trust of the mother dog is essential for conducting prolonged experiments on the puppies. The puppies also could show wide variations in their weight measurements depending upon the availability of resources in their surrounding environment. Another problem in establishing a weight chart for Indian free-ranging puppies is the high mortality rate of the puppies during the 
early weeks of their lives (Paul et al., 2016), making data collection till the end of the puppies' growth phase difficult. In this study, the growth pattern of a female Indian freeranging puppy living in an urban environment has been recorded.

\section{MATERIALS AND METHODS}

The study was conducted in Peerless Nagar, Sodepur $\left(22^{\circ}\right.$ $\left.41^{\prime} 54^{\prime \prime} \mathrm{N}, 88^{\circ} 23^{\prime} 22^{\prime \prime} \mathrm{E}\right)$, Panihati Municipality, North 24 Parganas district, West Bengal, India. The study was carried out from $11^{\text {th }}$ March 2020 to $8^{\text {th }}$ July 2020. Peerless Nagar consists of three dog groups. The dog group at the gate to Peerless Nagar was the only group with intact females, the rest were neutered. The gate dog group consisted of four females and two males. One of the female dogs (designated as DF1) gave birth in late February 2020 to eight puppies. Of the eight puppies only two female puppies survived to 5 weeks old. One of the two puppies died at 6 weeks old (car accident). The surviving puppy (designated as DF1D) was used in the experiment. The dogs in Peerless Nagar were provided with one meal of rice and dal everyday by the sweepers and security guards. This situation resulted in the dogs trusting the sweepers and security guards enough to allow them to touch both the adult dogs and the puppies without being bitten. The sweepers were the ones who handled the dogs during weight and length measurements under the supervision of the experimenter. The weight was taken with the instrument-Hesley Weighing Scale with Advanced Step on Technology (Company-Hesley Inc. Germany, Model- HSB1, Year-2018, Maximum weight-180 $\mathrm{kg}$, error-50g) and total length (from snout tip to end of tail) was taken with OFIXO Measuring tape (maximum length $150 \mathrm{~cm}$ ). The weight of the puppy (from 5 weeks to 12 weeks) was taken by placing the puppy on the weighing scale and recording the measurement. This step was repeated two times to get an accurate reading. The puppy's weight (from 13 weeks to 22 weeks) was taken by a sweeper lifting the puppy in his arms and the combined weight of the puppy and the sweeper being recorded. The weight of the sweeper was then subtracted from the combined weight. This step was repeated two times to get an accurate reading. The weight of the mother was taken by lifting the mother in the sweeper's arm and the combined weight of the sweeper and the mother was recorded. The weight of the sweeper was then subtracted from the combined weight. The process was repeated two times. The weight of the aunt of the puppy DF1D was taken only once in a similar manner in July near the end period of the study. The length measurements of DF1D were taken by one sweeper gently holding DF1D and another sweeper gently running the measuring tape from DF1D's snout tip to the end of her tail. The puppy DF1D's weight measurements were taken weekly. The length measurements of DF1D and the weight measurements of the mother dog DF1 were taken monthly (Fig 1). A total of 18 weight measurements of puppy DF1D, 5 length measurements of DF1D, 5 weight measurements of the mother dog DF1 and 1 weight measurement of DF1's sister was taken. The period of the puppy's weight gain observation was divided into three phases- (i) pre-weaned phase (5-10 weeks), (ii)weaned phase (11-16 weeks) and (iii) scavenge by itself phase (17-22 weeks). During the pre-weaned phase the puppy was suckling and eating food given by the mother and sweepers. During the weaned phase the puppy was eating food given by mother, sweepers and scavenging for food. Suckling had completely stopped during this time. During the scavenge by itself phase the puppy was eating food given by the sweepers and scavenging by itself, the mother had stopped giving the puppy food. Average weight gain during the three phases of observation was determined. The data were subjected to post hoc one way Anova test. The monthly weight gain and length increase of the puppy was determined and the data were subjected to Pearson correlation test. During the period of observation the puppy was injured four times-twice by car, once by adult dog and once infested with fleas. The average weight increase during the healthy and unhealthy phases of the puppy's life was determined. The data was subjected to paired t test. The percentage of monthly weight increase of the mother was determined. The Pearson correlation test was performed on the mother's monthly weight increase percentage and the months after birth of the puppy. All statistical analysis was performed using IBM SPSS Statistics 2019 software at West Bengal State University.

\section{RESULTS AND DISCUSSION}

The average weight of the puppy was observed to be $0.71 \pm$ $0.30 \mathrm{~kg}$ during the pre-weaned phase, $0.45+0.48 \mathrm{~kg}$ during the weaned phase and $0.38 \pm 0.40 \mathrm{~kg}$ during the scavenge by itself phase. Performance of post hoc one way Anova $[F(2,16)=0.935, p<0.416]$ showed that there was no significant difference in the weight gain in the three phases of

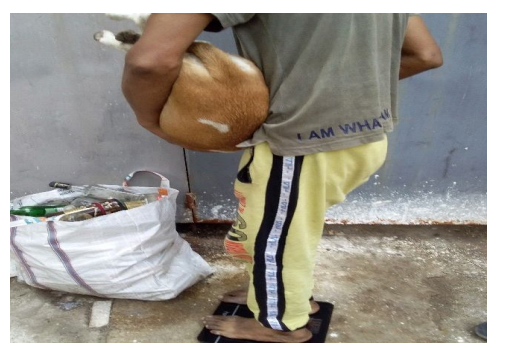

(a)

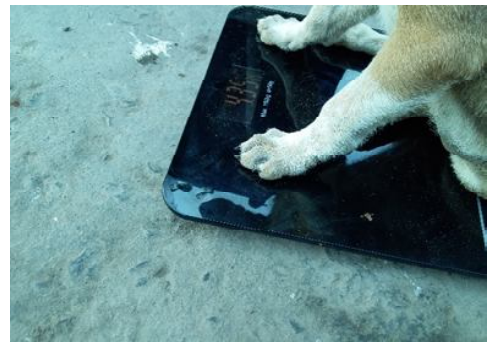

(b)

Fig 1: Photographs of the weight measurements(a) Mother DF1 (b) Puppy DF1D. 
observation (Fig 2 and 3). Average monthly weight gain of the pup was determined to be $1.95 \pm 0.587 \mathrm{~kg}$ and the average monthly length increase was determined to be $21.25 \pm 19.05 \mathrm{~cm}$ (Fig 4). We determined that there was no significant correlation between monthly weight gain and length increase of the puppy (Pearson Correlation test: $r=0.451, p<0.549)$. The average weight increase of the puppy during the healthy and unhealthy periods were determined to be $0.6722 \pm 0.227 \mathrm{~kg}$ and $0.1667 \pm 0.3316 \mathrm{~kg}$. There was a significant difference in the weight gain of the puppy during the healthy and unhealthy periods of observation (Paired $t$ test: $t=3.346, d f=8, p<0.01$ ). The average weight gain during the healthy period was 4 times the weight gain during the unhealthy period. The mother dog showed an average weight of $16.64 \pm 0.3305 \mathrm{~kg}$ during the five months of observation. There was no significant correlation between the percentage of weight gain of the mother dog and the months after birth of the puppy (Pearson Correlation test: $r=0.594, p<0.406)$. The weight of the mother dog was 17.1 $\mathrm{kg}$ and her sister (same mother, same litter and area) who was not pregnant was $20.1 \mathrm{~kg}$. The weight of the mother at the end of the observation was determined to be $14.92 \%$ less than her sister. The weight of the puppy at the end of the observation was $9.35 \mathrm{~kg}$. The puppy had gained $53.42 \%$ of the weight of her mother and $46.51 \%$ of the weight of her aunt at the end of the observation.

Dogs produce altricial puppies who are completely dependent on their mother for food and protection (Lezama et al., 2019). Milk production puts a significant strain on the body of the mother dog. The mother will on an average require 1.5-3 times their normal maintenance energy for milk production during the first month after birth (Fontaine, 2012). A diet rich in carbohydrate but with little to no animal protein as the one available to DF1 results in low energy and quicker exhaustion for working dogs than a high protein or fat rich diet (Hill, 1998). Studies on lactating mother dogs have found that mother dog utilising low energy rich diets lost nearly $3100 \mathrm{kcal}$ per $\mathrm{kg}$ of body weight (Case et al., 2011). Indian free-ranging mother dogs usually focus on regaining their health after weaning their puppies in order to focus on the next breeding season. Data showed that DF1's weight did not significantly improve even after a few months post weaning and she was $14 \%$ lighter than her sister. This could be due to the fact that shops in her territory were closed and human activity was reduced because of the lockdown imposed in India during the period of the study in response to the COVID-19 pandemic. Dogs show a period of maximum growth during the $2^{\text {nd }}$ to $5^{\text {th }}$ months of their life (Ardelean and Suteu, 2005). DF1D attained nearly $46-53 \%$ of the adult body during the first 22 weeks of her life. Indian free-ranging puppies remain huddled together with their siblings and mother in a secluded safe place for the first 2-4 weeks of their lives (Paul et al., 2014). So, the study could not determine the initial birth weight of DF1D or the average weight gain in the first month of her life but the study revealed that DF1D gained on an average nearly $2 \mathrm{~kg} /$ month for the next four months of her life. DF1D showed decrease in her body weight gain only during two situations- (a) due to sickness/injury and (b) at the time she was initially weaned. The dietary transition during weaning can lead to the puppy undergoing stress due to temporary lack of proper easily digestible nutrients in the form of mother's milk (Fontaine, 2012). DF1D was able to adjust to the dietary transition and began to steadily gain weight within 2 weeks after weaning. In the case of decrease in weight gain due to sickness or injury, car accidents caused the most harm to DF1D. DF1D lost weight in both cases of car accident. The relationship between Indian free-ranging dogs and humans is a "doubleedged sword" for the dogs. Although Indian free-ranging have been observed to hunt wildlife like spotted deer and blackbuck in Indira Gandhi National Park (Baskaran, 2017), but the dogs living in urban habitats are completely dependant on humans for their food (Bhadra and Bhadra, 2014). The puppies are especially dependant on human kindness for their survival. Domestic dogs unlike their wild relatives, the gray wolves (Canis lupus lupus) do not take care of their young for nearly two years and begin to compete with them for food soon after weaning at nearly 3 months old. The puppies at this time are dependent on human garbage and human kindness for food. Studies have shown that humans found dogs most attractive around 6.3-8.3 weeks (near completion of weaning phase) period of the dogs' lives. The puppies' attractiveness motivated the humans to care for the dogs during this crucial period of their lives (Chersini et al., 2018). This care of humans during the weaning phase of the Indian free-ranging dogs' lives

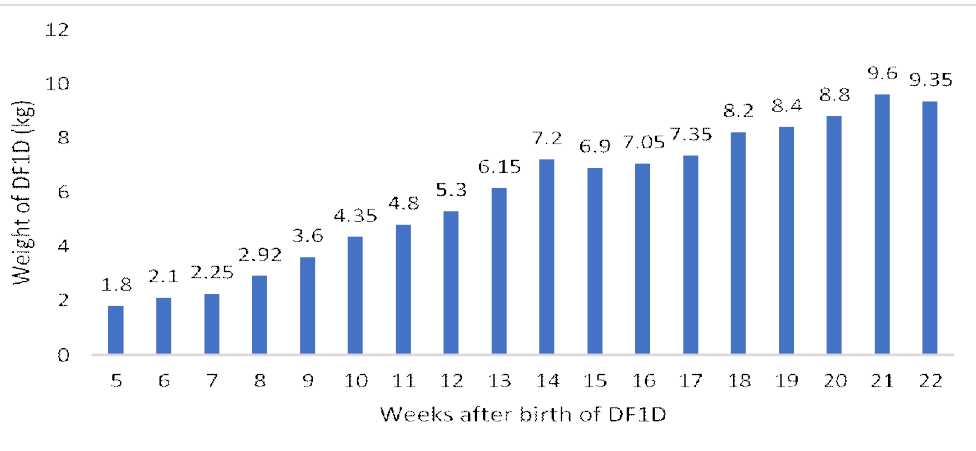

Fig 2: Graphical representation of growth pattern of DF1D. 


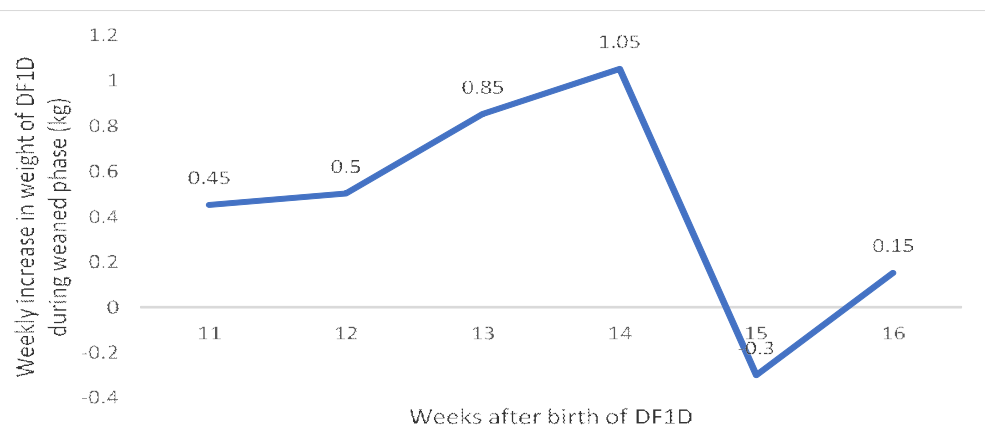

(a)

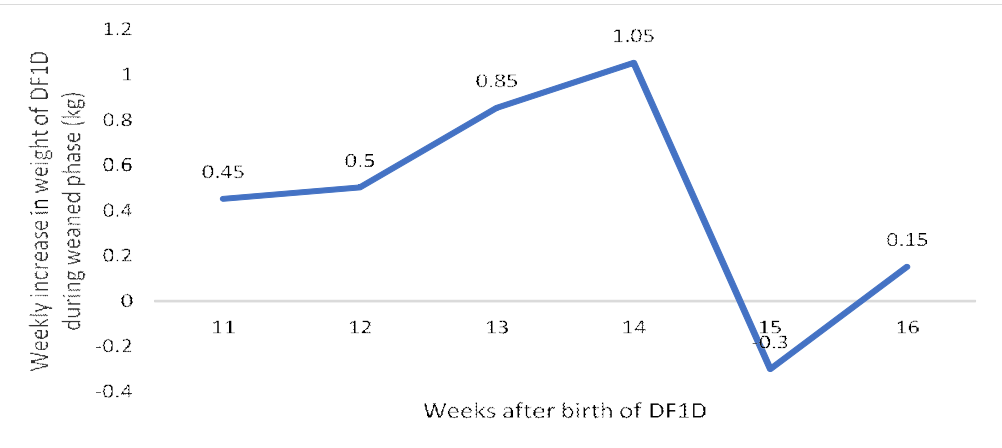

(b)

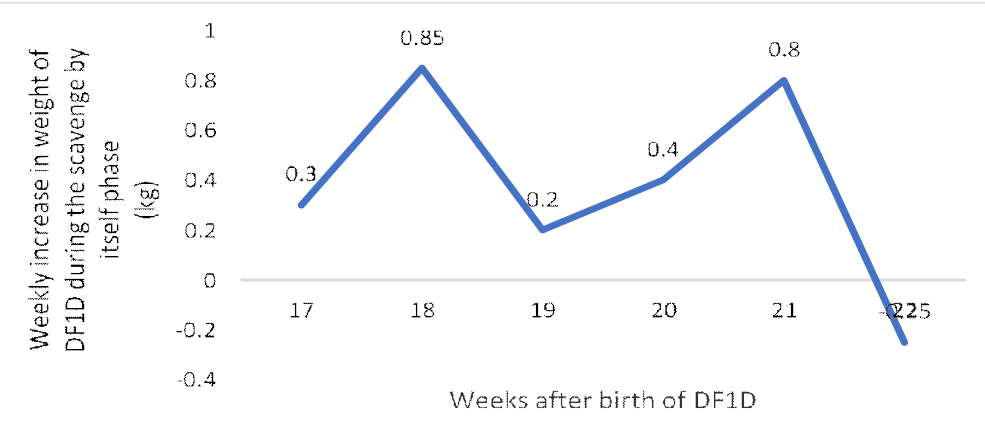

(c)

Fig 3: Graphical representation of weekly weight gain of DF1D.

(a) Drop in weight gain due to flea infestation in pre-weaned stage.

(b) Drop in weight gain due to car accident in weaned phase.

(c) Drop in weight gain due to adult dog attack and car accident respectively.

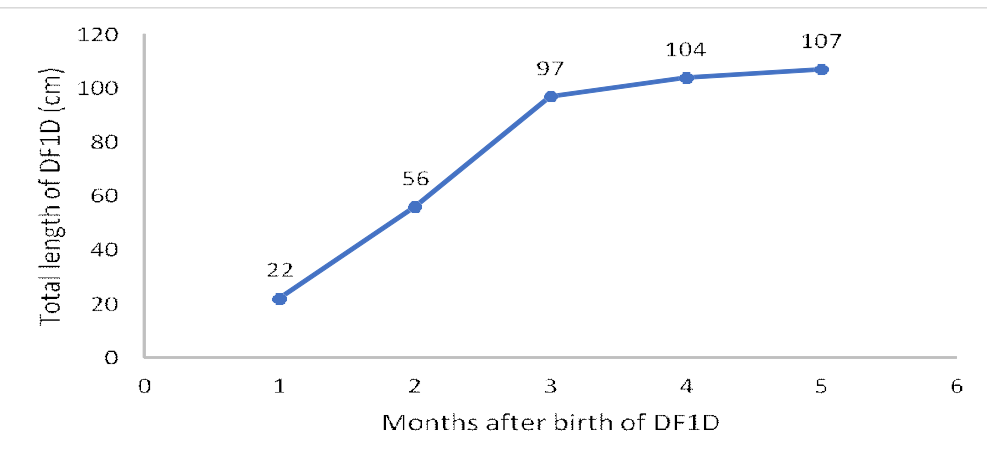

Fig 4: Graphical representation of increase in total length of DF1D during the study period. 
could have enabled them to get extra food from the humans increasing their chances of survival. At the same time studies have shown that humans were the major contributor (63\%) for all Indian free-ranging dog deaths (Paul et al., 2016). Maximum mortality occurs during the fourth month of the dogs' lives (Paul et al., 2016). DF1D was also injured by human activities in the period between the $14^{\text {th }}$ and $15^{\text {th }}$ week of her life. DF1D took nearly 4 weeks to completely recover from the accident. DF1D's sister also lost her life due to human activities. So, depending on the situation human influence can either be beneficial or detrimental for the dogs.

The establishment of a growth chart for Indian freeranging dogs will enable us to determine the optimal weight of the dogs during the various stages of the dogs' lives. It may help veterinarians to determine whether a rescued dog is possibly malnourished compared to its brethren or not. The growth chart could also be used to determine the age of rescued puppies.

This study had many limitations. Only one female individual was used in this study. No information regarding the growth pattern of a male puppy was obtained. Since only DF1D survived in the litter we could not determine how litter size affected the growth of puppies. We could not determine whether any variations existed between the growth pattern of male and female puppies. Another problem of the study was that DF1D received regular meals of rice with dal from people, other puppies may not have access to a regular supply of food which could affect their growth and development. Further research into this matter is necessary in the future.

\section{CONCLUSION}

The current study has shown that with regular food supply by humans, the Indian free-ranging puppy could reach nearly $50 \%$ of its adult body weight in the first five months of its life. The problem with the current method of age determination of the Indian free-ranging puppies, by looking at their teeth, is that the puppies start to lose their teeth anywhere from 3.5 months to 5 months. This problem makes exact age determination difficult. A growth chart establishment for these dogs will enable veterinarians to be better able to determine their age and health status.

\section{REFERENCES}

Ardelean, A. and Suteu, E. (2005). The estimation of the growth curve at dog. Buletin USAMV-CN. 63: 175-181.

Baskaran, S.T. (2017). The Book of Indian Dogs, $1^{\text {st }}$ ed. Rupa Publications India, Daryaganj, New Delhi. Pp 141-148.

Bhadra, A. and Bhadra, A. (2014). Preference for meat is not innate in dogs. Journal of Ethology. 32: 15-22.
Case, L., Daristotle, L., Hayek, M. and Raasch, M. (2011). Canine and Feline Nutrition: A Resource for Companion Animals Professionals. $3^{\text {rd }}$ ed. Mosby, St. Louis, Missouri. Pp-199-209.

Chersini, N., Hall, N. and Wynne, C. (2018). Dog pups' attractiveness to humans peaks at weaning age. Anthrozoos. 31: 309318. https://doi.org/10.1080/08927936.2018.1455454.

Davis, S.J.M. and Valla. (1978). Evidence for domestication of dogs, 12,000 years ago in the Natufian of Israel. Nature. 278: 608-610.

Fontaine, E. (2012). Food intake and nutrition during pregnancy, lactation and weaning in the Dam and Offspring. Reproduction of Domestic Animals. 47: 873-1061.

Hill, C. (1998). The nutritional requirements of exercising dogs. Journal of Nutrition. 128: 2686-2690.

Lezama, K.G., Mariti, C., Mota, D.R., Burnes, J.M., Garcia, H.B. and Gazzano. (2019). Maternal Behaviour in domestic dogs. Journal of Veterinary Medicine Science. 7: 20-30.

Majumdar, S., Bhadra, A., Ghosh, A., Mitra, S., Bhattacharjee, D., Chatterjee, J., Nandi, A . (2014). To be or not to be social: Foraging associations of free-ranging dogs in an urban ecosystem. Acta Ethologica. 17: 1-8.

Olliver, M., Tresset, A., Bastian, F., Lagoutte, L., Axelsson, E., Arendt, M.L., Balasescu, A., Marshour, M., Sablin, M., Salanova, L., Vigne ,J.D., Hitte, C. and Hanni, C. (2016). Amy2B copy number variation reveals starch diet adaptations in ancient European dogs. Royal Open Society Science. 11:160449. https://doi.org/10.1098/rsos.160449.

Pal, S., Ghosh, B. and Roy, S. (1998). Agonistic behaviour of freeranging dogs Canis familiaris in relation to season, sex and age. Applied Animal Behaviour Science. 59: 331-348. https://dx.doi.org/10.1016/S0168-1591(98)00108-7.

Pal, S. (2003). Reproductive behaviour of free-ranging urban dogs in West Bengal. Acta Theriol. 48: 271-281.

Pal, S. (2005). Parental care in free-ranging dogs, Canis familiaris. Applied Animal Behaviour Science. 90: 31-47.

Pal, S. (2008). Maturation and development of social behaviour during early ontogeny in free-ranging dog puppies in West Bengal, India. Applied Animal Behaviour Science. 111: 95-107.

Paul, M., Majumdar, S. and Bhadra, A. (2014). Selfish mothers? An empirical test of parent-offspring conflict over extended parental care. Behavioural Processes. 103: 17-22. https:// dxdoi.org/10.1016/j.beproc.2013.10.006.

Paul, M., Majumdar, S., Sau, S., Nandi, A. and Bhadra, A. (2016). High early life mortality in free-ranging dogs is largely influenced by humans. Science Reports. 6: 19641.

Serpell, J. (1995). The domestic dog: its evolution, behaviour and interactions with people, $1^{\text {st }}$ ed. Cambridge. University Press, Cambridge. Pg-14.

Vanak, A. and Gompper, M. (2009). Dietary niche separation between sympatric free-ranging domestic dogs and Indian foxes in Central India. Journal of Mammology. 90:1058-1065. 